\title{
Pain-related anxiety influences pain perception differently in men and women: A quantitative sensory test across thermal pain modalities
}

\author{
Michel A. Thibodeau ${ }^{\mathrm{a}, *}$, Patrick G. Welch ${ }^{\mathrm{a}}$, Joel Katz ${ }^{\mathrm{b}}$, Gordon J.G. Asmundson ${ }^{\mathrm{a}}$ \\ a Department of Psychology, University of Regina, Regina, Saskatchewan, Canada S4S OA2 \\ ${ }^{\mathrm{b}}$ Department of Psychology and School of Kinesiology and Health Science, York University, Toronto, Ontario, Canada BSB 232
}

Sponsorships or competing interests that may be relevant to content are disclosed at the end of this article.

A R T I C L E I N F O

\section{Article history:}

Received 23 June 2012

Received in revised form 22 November 2012

Accepted 1 December 2012

\section{Keywords:}

Anxiety sensitivity

Depression

Fear of pain

Pain perception

Pain-related anxiety

Sex differences

\begin{abstract}
A B S T R A C T
The sexes differ with respect to perception of experimental pain. Anxiety influences pain perception more in men than in women; however, there lacks research exploring which anxiety constructs influence pain perception differentially between men and women. Furthermore, research examining whether depression is associated with pain perception differently between the sexes remains scant. The present investigation was designed to examine how trait anxiety, pain-related anxiety constructs (ie, fear of pain, pain-related anxiety, anxiety sensitivity), and depression are associated with pain perception between the sexes. A total of 95 nonclinical participants (55\% women) completed measures assessing the constructs of interest and participated in quantitative sensory testing using heat and cold stimuli administered by a Medoc Pathway Pain and Sensory Evaluation System. The findings suggest that pain-related anxiety constructs, but not trait anxiety, are associated with pain perception. Furthermore, these constructs are associated with pain intensity ratings in men and pain tolerance levels in women. This contrasts with previous research suggesting that anxiety influences pain perception mostly or uniquely in men. Depression was not systematically associated with pain perception in either sex. Systematic relationships were not identified that allow conclusions regarding how fear of pain, pain-related anxiety, and anxiety sensitivity may contribute to pain perception differentially in men and women; however, anxiety sensitivity was associated with increased pain tolerance, a novel finding needing further examination. The results provide directions for future research and clinical endeavors and support that fear and anxiety are important features associated with hyperalgesia in both men and women.
\end{abstract}

\section{Introduction}

Chronic pain is more prevalent in women [18], which theorists suggest may be attributable to psychological factors [21,44]. For instance, women typically experience greater fear of pain (ie, cognitive, emotional, behavioral, and physiological reaction to immediate or immanent pain) [3,9], pain-related anxiety (ie, future-oriented cognitive-emotional state focusing on potential pain) $[1,9]$, and anxiety sensitivity (ie, the fear of anxiety sensations and putative vulnerability factor for development of chronic pain) [9,50]. These constructs theoretically contribute to avoidance of activities that may be associated with further pain but that would promote healing (eg, exercise), thereby contributing to progression from acute to chronic pain $[4,5,35,57]$.

Experimental studies demonstrate that women also experience greater pain perception (ie, hyperalgesia) compared to men

\footnotetext{
* Corresponding author. Tel.: +1 (306) 337 2473; fax: +1 (306) 3373275.

E-mail address: mikethibodeau@gmail.com (M.A. Thibodeau).
}

$[18,19,21]$. Again, these differences may be due in part to greater rates of fear of pain $[23,28]$, pain-related anxiety [49,53], and anxiety sensitivity in women [39,55], as each of these are associated with hyperalgesia. Women also experience greater trait anxiety (ie, long-lasting propensity to experiencing general anxiety) [17] and depression [38], which have been associated with hyperalgesia $[6,21,30,32,52]$.

Given the above findings, it is possible that higher rates of anxiety in women explain why they report greater experimental pain; however, research to date provides little support for this possibility. Indeed, several studies have demonstrated that trait anxiety and state anxiety (ie, anxiety in the present moment) are associated with hyperalgesia only in men $[20,31,32]$, and anxiety constructs seem to be associated with pain exacerbation in men but not women with chronic pain $[16,44,45]$. Moreover, studies exploring sex-specific associations between pain-related anxiety constructs (eg, pain-related anxiety) and pain perception report inconsistent results (eg, significant effects only in women [53,57], in both sexes $[33,51])$, further obfuscating conclusions regarding sex-specific associations between hyperalgesia and anxiety. The 
need to further explore the association between pain-related anxiety constructs and pain perception in both sexes has been explicitly mentioned in recent literature [55], and Fillingim et al. recently concluded in a comprehensive review that "whether depression influences pain perception differently among women vs men is not yet known" [21]. Advances in this area may inform which long-lasting predispositions (ie, as opposed to state anxiety) could contribute to hyperalgesia or hypoalgesia (ie, reduced pain perception) differently between sexes, guiding contemporary theory $[4,5,35,57]$ and chronic pain interventions targeting these predispositions $[14,56,58]$.

The current status of literature points to 4 issues that warrant examination: (a) whether pain-related anxiety constructs or trait anxiety are associated with experimental pain perception, (b) if anxiety constructs are associated with experimental pain differently between sexes, (c) if depression symptoms are associated with pain perception differently between sexes, and (d) how trait anxiety, fear of pain, pain-related anxiety, anxiety sensitivity, and depression symptoms differ in their relationships to experimental pain when these are considered concurrently. The purpose of this investigation was to address these issues while minimizing potential confounds (eg, medical conditions) and generalizing the findings to both heat and cold stimuli and multiple indices of pain perception (ie, pain threshold, tolerance, intensity, unpleasantness).

\section{Materials and methods}

\subsection{Participants}

Ethical approval for this investigation was obtained from the University of Regina Research Ethics Board. After providing consent to participate, a total of 241 university students and community members ( 156 women and 85 men; age $18-55$ years; mean \pm standard deviation age $26.43 \pm 9.43$ years) completed a brief screening questionnaire to assess for exclusion criteria. Given the associations between pain perception and a number of psychological and medical conditions [34], 87 respondents who self-reported one of the following conditions were not invited to participate in the quantitative sensory testing procedures: a current diagnosis of a mental disorder, current or past chronic pain, current or past diagnosis of a medical condition suspected or known of being associated with pain sensitivity (eg, fibromyalgia, diabetes, irritable bowel syndrome), current analgesic medication use (other than occasional over-the-counter analgesics use), psychotropic medication use involving a dosage change within the past 2 months, or having a current condition that may render the participant unable to complete the research tasks condition (eg, skin lesions). Excluded participants were statistically significantly older than those who were not excluded $(t=2.99, P<.05)$ and more women were excluded relative to men $\left(\chi^{2}=15.84, P<.001\right)$. A total of 154 participants (84 women, 70 men, aged 18-52 years, $24.68 \pm$ 7.42 years) were subsequently invited to the laboratory and a total of 95 participants (52 women, aged 18-52 years, $25.04 \pm$ 8.74 years; 43 men, aged $18-40$ years, $23.70 \pm 5.00$ years) participated in quantitative sensory testing. Individuals who participated in quantitative sensory testing and those who declined the invitation were similar in age $(t=1.45, P>.10)$ and in sex $\left(\chi^{2}=.42\right.$, $P>.50$ comparing the ratio of men to women). Self-reported demographic information revealed that most women identified as white (90\%), that most women were current students (65\%), and that approximately half of women reported being part-time $(31 \%)$ or full-time (25\%) employed. Self-reported demographic information for men was similar to that of women, with most men identifying as white (88\%) and as current students (65\%), and approximately half of men being part-time (26\%) or full-time (28\%) employed.

\subsection{Measures}

\subsubsection{State-Trait Anxiety Inventory, Trait (STAI-T)}

The STAI-T is a 20-item self-report rating scale that measures trait anxiety (ie, a long lasting propensity to experiencing general anxiety) [48]. Each item is rated on a 4-point Likert scale ranging from 1 (almost never) to 4 (almost always). The STAI-T has demonstrated good reliability and validity in previous studies $[30,48]$. For the current sample, internal consistency was good $(\alpha=.89)$.

\subsubsection{Fear of Pain Questionnaire-Short Form (FPQ-SF)}

The FPQ-SF is a 20-item self-report measure designed to assess fear of pain (ie, a present-oriented state focused on immediate or immanent pain associated with cognitive, emotional, physiological, and behavioral expressions) relating to various circumstances [3]. Each item (eg, "Biting your tongue while eating," "Having someone slam a heavy car door on your hand") is rated with a 5-point Likert scale ranging from 1 (not at all) to 5 (extreme). The FPQ-SF has demonstrated good factorial validity and internal consistency in past samples $[3,9]$. For the current sample, internal consistency was good $(\alpha=.86)$.

\subsubsection{Pain Anxiety Symptoms Scale-Short Form (PASS-20)}

The PASS-20 is a 20-item self-report rating scale that measures pain-related anxiety (ie, a future-oriented state focused on potential pain associated with cognitive and behavioral components and a weaker but prolonged state of physiological arousal) [36]. Each item (eg, "Pain sensations are terrifying," "I worry when I am in pain") is rated with a 6-point Likert scale ranging from 0 (never) to 5 (always). The PASS-20 has demonstrated factorial invariance in clinical pain populations $[9,10]$ as well as in nonclinical populations [1], supporting the validity of the measure. For the current sample, internal consistency was excellent $(\alpha=.91)$.

\subsubsection{Anxiety Sensitivity Index-3 (ASI-3)}

The ASI-3 is an 18-item self-report questionnaire designed to measure anxiety sensitivity (ie, the fear of anxiety-related sensations based on the belief that they have harmful consequences) [54]. Items in the ASI-3 (eg, "When I feel pain in my chest, I worry that I'm going to have a heart attack," "When I feel 'spacey' or spaced out I worry that I may be mentally ill") are rated on 5-point Likert scales ranging from 1 (agree very little) to 5 (agree very much). The ASI-3 has demonstrated factorial, convergent, discriminant, and criterion-related validity [54]. For the current sample, internal consistency was good $(\alpha=.81)$.

\subsubsection{Beck Depression Inventory-II (BDI-II)}

The BDI-II is a 21-item self-report rating scale that measures the existence and severity of depression symptoms. All but 2 of the items are rated with a 4-point Likert scale ranging from 0 (eg, "I do not feel sad") to 3 (eg, "I am so sad or unhappy that I can't stand $i t$ ") and the final 2 items (ie, "changes in sleeping pattern," "changes in appetite") include additional response options to identify the direction (increase, decrease) of behavior change [8]. The BDI-II has demonstrated good internal consistency in previous studies [6-8]. For the current sample, internal consistency was good $(\alpha=.87)$.

\subsubsection{Numeric Rating Scales (NRS)}

NRS were used to measure the subjective experience of pain intensity and unpleasantness. As used in previous studies [22], a 101-point scale ranging from 0 (no pain at all) to 100 (worst imaginable pain) was used to measure pain intensity. The pain unpleasantness NRS ranged from 0 (not unpleasant at all) to 100 (most 
unpleasant pain imaginable). NRSs have been demonstrated to enable accurate discrimination of perceived differences of $0.5^{\circ} \mathrm{C}$ [42].

\section{Equipment and procedure}

Thermal stimulation was delivered via the Medoc Pathway Pain and Sensory Evaluation System, ATS model (Medoc Advanced Medical Systems Ltd, Ramat Yishay, Israel). The Pathway system allows for precise and programmable control of heat and cold stimuli using the Advanced Thermal Stimulator thermode. The Advanced Thermal Stimulator thermode has a $30 \times 30 \mathrm{~mm}$ square contact and can produce temperatures between $0^{\circ} \mathrm{C}$ and $55^{\circ} \mathrm{C}$ at a rate of change of up to $8^{\circ} \mathrm{C}$ per second.

\subsection{Equipment}

\subsection{General procedure}

A male experimenter greeted all participants and guided participants throughout the experimental procedure. Participants completed the self-report questionnaires before the quantitative sensory testing procedures, which required approximately $20 \mathrm{~min}$. Participants were subsequently given a semi-structured verbal description of the quantitative sensory testing procedures. After the description, the thermode was attached to the dorsal surface of the participant's right hand (ie, the top side of the right hand). In 2 participants, 1 man and 1 woman, the thermode was attached to the left hand because of previous injuries because they had experienced injury to their right arm and/or hand. (Analyses were conducted with and without the inclusion of these 2 participants, and the results were nearly identical [ie, statistical significance, direction, and size of relationships did not vary]; consequently, these participants were not excluded from the following analyses.) In all cases, the thermode-attached hand was then placed on a computer mouse so that participants could signal feedback during the tasks.

Quantitative sensory testing followed 2 procedures. First, participants engaged in pain threshold and tolerance testing, which was adopted from a previously standardized quantitative sensory testing procedure [46] and combined methods used in a recent investigation on pain perception [19]. Second, participants engaged in pain intensity and unpleasantness estimations [13,25,41]. The quantitative sensory testing procedures lasted approximately $90 \mathrm{~min}$.

\subsection{Pain threshold and tolerance testing tasks}

Testing was conducted to determine heat pain threshold, cold pain threshold, heat pain tolerance, and cold pain tolerance. Each variable was estimated by averaging a participant's responses over 3 trials, with an intertrial interval of $30 \mathrm{~s}$. All trials began at a baseline temperature of $32^{\circ} \mathrm{C}$ and increased or decreased in temperature at a rate of $1^{\circ} \mathrm{C}$ per second for heat and cold pain threshold [46] and a similar methodology was originally adopted for pain tolerance trials; however, pilot testing demonstrated that several participants did not report intolerable pain during tolerance trials when facing the most extreme thermal stimuli. Temperature changes during tolerance trials were thus set at a rate of $0.5^{\circ} \mathrm{C}$ per second to increase the duration of the thermal stimuli and increase reports of pain [37]. Trials ended when participants pressed the mouse button, signaling that they could: (a) just perceive the sensation of heat pain (ie, heat pain threshold); (b) just perceive the sensation of cold pain (ie, cold pain threshold); (c) feel that the heat pain had become intolerable (ie, heat pain tolerance); or (d) feel that the cold pain had become intolerable (ie, cold pain tolerance). If on any trial the thermode reached the maximum (ie, $51^{\circ} \mathrm{C}$ ) or the minimum (ie, $0^{\circ} \mathrm{C}$ ) temperature, the trial was discontinued and the result was set to that temperature.

\subsection{Pain intensity and unpleasantness estimations}

Magnitude estimations were conducted using 6 fixed-temperature heat trials $\left(40^{\circ} \mathrm{C}, 42^{\circ} \mathrm{C}, 44^{\circ} \mathrm{C}, 46^{\circ} \mathrm{C}, 48^{\circ} \mathrm{C}, 50^{\circ} \mathrm{C}\right)$ and 6 fixed-temperature cold trials $\left(10^{\circ} \mathrm{C}, 8^{\circ} \mathrm{C}, 6^{\circ} \mathrm{C}, 4^{\circ} \mathrm{C}, 2^{\circ} \mathrm{C}, 0^{\circ} \mathrm{C}\right)$. Each trial began at a baseline temperature of $32^{\circ} \mathrm{C}$ and ramped up or down at a rate of $2{ }^{\circ} \mathrm{C}$ per second until the trial target temperature was reached, which was then held for $5 \mathrm{~s}$ before returning to the baseline temperature at a rate of $8^{\circ} \mathrm{C}$ per second [25]. Participants remained at the baseline temperature for $1 \mathrm{~min}$ before commencing the next trial. During the 1-min intertrial interval, participants were asked to rate the pain intensity and unpleasantness experienced during the just experienced temperature using the NRS. Participants were asked to select the number on the NRS that best represented the intensity and unpleasantness of their pain experience. To counterbalance the potential impact that rating pain intensity first may have on subsequent ratings of pain unpleasantness, and vice-versa, the presentation orders of soliciting intensity and unpleasantness ratings were counterbalanced. Participants were given a manual trigger and informed that they could abort the magnitude estimation task at any time if the pain became intolerable by pressing the trigger button. If pressed, their NRS ratings for that trial were set to the maximum possible (ie, 100). Participants who rated the intensity or unpleasantness of the previous stimuli as greater than 80 , as well as those who aborted the previous task, were asked if they wanted to participate in any temperature levels that were more extreme. If they chose to skip those temperature levels, their NRS ratings for those trials were set to the highest possible (ie, 100).

\subsection{Analyses}

Descriptive statistics were first conducted for the STAI-T, FPQSF, PASS-20, ASI-3, BDI-II, and pain threshold, tolerance, intensity, and unpleasantness. Independent-samples $t$-tests were conducted to test for sex differences on these variables. Separate bivariate correlations were conducted for each sex to broadly examine the relationships of interest. Subsequently, simultaneous regression analyses were conducted to examine the joint and unique variance accounted for by STAI-T, FPQ-SF, PASS-20, ASI-3, and BDI-II scores in the pain variables. Regression analyses were conducted for men and women separately. Due to significant and large correlations between self-reported pain intensity and unpleasantness scores (all $r>.90$, all $P<.001$ ), as well as the redundancy of the findings (ie, pain unpleasantness exhibited the same patterns of significance and directionality of effect as pain intensity), analyses including pain unpleasantness are excluded for brevity but are available from the authors upon request.

\section{Results}

\subsection{Descriptive statistics and sex differences}

Descriptive data and sex differences on the variables of interest are reported in Table 1. Accurate heat and cold pain tolerance levels could not be obtained in a proportion of participants who were able to withstand the highest $\left(51^{\circ} \mathrm{C}\right)$ and lowest $\left(0^{\circ} \mathrm{C}\right)$ temperatures without reporting that the pain had become intolerable. Specifically, 8 (19\%) men and 1 (2\%) woman received the highest temperature without reaching a heat pain tolerance threshold and 32 (74\%) men and 22 (42\%) women received the lowest temperature without reaching a cold pain tolerance threshold. The analyses were rerun including only individuals whose pain tolerance thresholds were reached; however, the results of these analyses are excluded because they are associated with poor statistical power for cold pain (ie, they include only 11 men and 30 women) and because the results are not statistically different for heat pain 
Table 1

Descriptive statistics of variables and sex differences.

\begin{tabular}{|c|c|c|c|c|c|c|}
\hline \multirow[t]{2}{*}{ Measure } & \multicolumn{2}{|l|}{ Men $(n=43)$} & \multicolumn{2}{|c|}{ Women $(n=52)$} & \multirow[t]{2}{*}{$t$} & \multirow[t]{2}{*}{$d$} \\
\hline & Range & Mean \pm SD & Range & Mean \pm SD & & \\
\hline STAI-T & $21-57$ & $33.7 \pm 8.75$ & $21-52$ & $31.87 \pm 6.88$ & 1.14 & 0.23 \\
\hline FPQ-SF & $20-59$ & $36.23 \pm 9.26$ & $22-72$ & $37.23 \pm 9.80$ & -0.51 & 0.1 \\
\hline PASS-20 & $0-56$ & $16.44 \pm 12.82$ & $0-49$ & $20.38 \pm 12.14$ & -1.54 & 0.21 \\
\hline ASI-3 & $0-36$ & $10.81 \pm 7.46$ & $0-29$ & $8.08 \pm 5.65$ & $2.03^{*}$ & 0.31 \\
\hline BDI-II & $0-23$ & $5.23 \pm 5.79$ & $0-25$ & $4.35 \pm 5.00$ & 0.8 & 0.16 \\
\hline Heat pain threshold & $36.92-49.88$ & $45.46 \pm 3.05$ & $36.90-49.77$ & $43.52 \pm 3.71$ & $2.75^{* *}$ & 0.57 \\
\hline Heat pain tolerance & $46.26-51.00$ & $49.47 \pm 1.32$ & $42.64-51.00$ & $47.77 \pm 2.13$ & $4.77^{* * *}$ & 0.96 \\
\hline Cold pain threshold & $0-35.98$ & $14.11 \pm 10.28$ & $0-29.32$ & $17.99 \pm 9.60$ & $-1.90^{\dagger}$ & 0.39 \\
\hline Cold pain tolerance & $0-17.25$ & $1.69 \pm 3.81$ & $0-26.2$ & $5.5 \pm 7.23$ & $-3.29^{* *}$ & 0.66 \\
\hline $40^{\circ} \mathrm{C}$ intensity & $0-10$ & $0.44 \pm 1.86$ & $0-0$ & $0.00 \pm 0.00$ & 1.72 & 0.33 \\
\hline $42^{\circ} \mathrm{C}$ intensity & $0-40$ & $2.81 \pm 7.65$ & $0-20$ & $1.65 \pm 4.04$ & 0.95 & 0.19 \\
\hline $44^{\circ} \mathrm{C}$ intensity & $0-45$ & $5.56 \pm 10.59$ & $0-35$ & $6.08 \pm 9.18$ & -0.26 & 0.05 \\
\hline $46^{\circ} \mathrm{C}$ intensity & $0-52$ & $11.19 \pm 14.75$ & $0-70$ & $17.66 \pm 19.05$ & -1.82 & 0.38 \\
\hline $48^{\circ} \mathrm{C}$ intensity & $0-100$ & $38.21 \pm 26.76$ & $1-100$ & $44.65 \pm 32.02$ & -1.05 & 0.22 \\
\hline $50^{\circ} \mathrm{C}$ intensity & $4-100$ & $64.98 \pm 27.42$ & $10-100$ & $75.65 \pm 28.48$ & $-1.85^{\dagger}$ & 0.41 \\
\hline $10^{\circ} \mathrm{C}$ intensity & $0-70$ & $7.47 \pm 15.70$ & $0-65$ & $8.73 \pm 15.83$ & -0.39 & 0.08 \\
\hline $8^{\circ} \mathrm{C}$ intensity & $0-78$ & $12.32 \pm 19.29$ & $0-65$ & $13.04 \pm 18.36$ & -0.18 & 0.04 \\
\hline $6^{\circ} \mathrm{C}$ intensity & $0-95$ & $15.30 \pm 23.19$ & $0-99$ & $18.80 \pm 23.07$ & -0.73 & 0.15 \\
\hline $4^{\circ} \mathrm{C}$ intensity & $0-95$ & $18.95 \pm 24.68$ & $0-100$ & $24.98 \pm 26.17$ & -1.15 & 0.23 \\
\hline $2^{\circ} \mathrm{C}$ intensity & $0-100$ & $23.33 \pm 26.35$ & $0-100$ & $32.38 \pm 29.74$ & -1.56 & 0.38 \\
\hline $0^{\circ} \mathrm{C}$ intensity & $0-90$ & $29.33 \pm 27.83$ & $0-100$ & $39.1 \pm 31.60$ & -1.58 & 0.33 \\
\hline
\end{tabular}

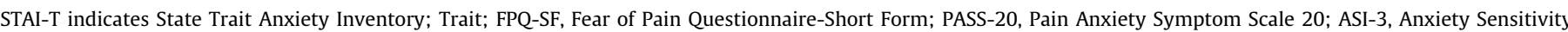
Index 3; and BDI-II, Beck Depression Inventory II.

${ }^{\dagger} P<.10$

* $P<.05$

${ }^{*} P<.01$

(ie, statistical significance of predictors do not change; size and direction of relationships are similar).

Women reported significantly greater ASI-3 scores than men. No other sex differences were identified on the psychological measures. Women exhibited significantly lower heat pain threshold, heat pain tolerance, and cold pain tolerance levels than men, consistent with previous literature $[21,40,43]$. Women also exhibited lower cold pain threshold levels than men but the findings were not statistically significant.

\subsection{Correlation and regression results}

Results of correlational analyses among the psychological variables, and among the psychological and pain variables are reported in Tables 2 and 3, respectively. The direction and size of the correlations between the psychological variables were similar for men and women. With respect to pain variables, STAI-T scores were positively correlated with cold pain intensity ratings for men $\left(8^{\circ} \mathrm{C}, 6^{\circ} \mathrm{C}, 2^{\circ} \mathrm{C}\right)$, but not with any pain variables for women. FPQSF scores were positively correlated with both heat $\left(40^{\circ} \mathrm{C}, 42^{\circ} \mathrm{C}\right.$, $\left.44^{\circ} \mathrm{C}\right)$ and cold $\left(10^{\circ} \mathrm{C}, 8^{\circ} \mathrm{C}, 6^{\circ} \mathrm{C}, 4^{\circ} \mathrm{C}, 2^{\circ} \mathrm{C}, 0^{\circ} \mathrm{C}\right)$ pain intensity ratings for men, and were inversely correlated with heat pain threshold and tolerance and cold pain tolerance levels in women. PASS-20

Table 2

Pearson correlations $(r)$ between psychological variables for each sex. ${ }^{\text {a }}$

\begin{tabular}{|c|c|c|c|c|c|}
\hline & STAI-T & FPQ-SF & PASS-20 & ASI-3 & BDI-II \\
\hline STAI-T & & .15 & .20 & $.38^{* *}$ & $.70^{* *}$ \\
\hline FPQ-SF & .20 & $\ldots$ & $.36^{* *}$ & .26 & .24 \\
\hline PASS-20 & .22 & $.46^{* * *}$ & $\ldots$ & $.56^{* *}$ & $.34^{*}$ \\
\hline ASI-3 & $.59^{* *}$ & $.32^{*}$ & $.38^{*}$ & $\ldots$ & $.45^{* *}$ \\
\hline BDI-II & $.80^{* *}$ & .17 & .13 & $.59^{* *}$ & $\ldots$ \\
\hline
\end{tabular}

STAI-T indicates State Trait Anxiety Inventory; Trait; FPQ-SF, Fear of Pain Questionnaire-Short Form; PASS-20, Pain Anxiety Symptom Scale 20; ASI-3, Anxiety Sensitivity Index 3; and BDI-II, Beck Depression Inventory II.

${ }^{a}$ Correlations for women are in boldface type.

${ }^{*} P<.05$

** $P<.01$ scores were inversely correlated with cold pain tolerance levels and positively correlated with heat $\left(40^{\circ} \mathrm{C}, 42^{\circ} \mathrm{C}, 44^{\circ} \mathrm{C}\right)$ and cold $\left(6^{\circ} \mathrm{C}, 4^{\circ} \mathrm{C}, 2^{\circ} \mathrm{C}, 0^{\circ} \mathrm{C}\right)$ pain intensity ratings in men, but were not correlated with any pain variables in women. ASI-3 scores were positively correlated with heat $\left(44^{\circ} \mathrm{C}, 46^{\circ} \mathrm{C}, 48^{\circ} \mathrm{C}\right)$ and cold $\left(8^{\circ} \mathrm{C}, 6^{\circ} \mathrm{C}\right.$ $4^{\circ} \mathrm{C}, 2^{\circ} \mathrm{C}, 0^{\circ} \mathrm{C}$ ) pain intensity ratings in men, and were correlated with greater cold pain tolerance in women (ie, hypoalgesia). BDIII scores were uncorrelated with any pain variables, with the exception of being significantly positively correlated with pain intensity ratings at $8^{\circ} \mathrm{C}$ in men.

The results of regression equations including total STAI-T, FPQSF, PASS-20, ASI-3, and BDI-II scores predicting the pain variables for each sex are reported in Tables 4 and 5 . The relative contributions of the variables of interest in predicting heat pain and cold pain threshold and tolerance levels for each sex are illustrated in Fig. 1. The regressions did not significantly predict heat pain thresholds for men or women. The regressions predicted a large minority of variance in heat (28\%) and cold (33\%) pain tolerance levels in women, while they failed to do so in men. FPQ-SF and ASI-3 scores were the only variables to predict unique variance in heat pain tolerance levels in women, with FPQ-SF scores being associated with lower pain tolerance levels and ASI-3 scores being associated with greater pain tolerance levels. The regressions did not predict significant variance in cold pain thresholds for either women or men. Moreover, the equations did not predict significant variance in cold pain tolerance for men, but did in women. FPQ-SF and ASI-3 scores were the only variables to predict unique variance in cold pain tolerance in women, with FPQ-SF scores being associated with less pain tolerance and ASI-3 scores being associated with greater pain tolerance.

The relative contributions of the variables of interest in predicting heat pain and cold pain intensity ratings for each sex are illustrated in Figs. 2 and 3. The regression equations did not significantly predict variance in any of the 12 pain intensity ratings for women. In contrast, the regression equations significantly predicted variance in the heat pain intensity ratings of men for milder heat pain (ie, $42^{\circ} \mathrm{C}, 44^{\circ} \mathrm{C}, 46^{\circ} \mathrm{C}$ ) but not the lowest (ie, $40^{\circ} \mathrm{C}$ ) or 2 highest (ie, $48^{\circ} \mathrm{C}, 50^{\circ} \mathrm{C}$ ) heat stimuli. The regression equations 
Table 3

Sex-specific bivariate Pearson correlations between psychological variables and pain variables.

\begin{tabular}{|c|c|c|c|c|c|c|c|c|c|c|}
\hline \multirow[t]{2}{*}{ Variable } & \multicolumn{2}{|l|}{ STAI-T } & \multicolumn{2}{|l|}{ FPQ-SF } & \multicolumn{2}{|c|}{ PASS-20 } & \multicolumn{2}{|l|}{ ASI-3 } & \multicolumn{2}{|l|}{ BDI-II } \\
\hline & Men & Women & Men & Women & Men & Women & Men & Women & Men & Women \\
\hline Heat pain threshold & .16 & .07 & -.01 & $-.28^{*}$ & -.23 & .14 & .08 & .19 & .15 & .06 \\
\hline Heat pain tolerance & .02 & -.05 & .03 & $-.29^{*}$ & -.17 & .16 & .16 & .27 & -.09 & -.13 \\
\hline Cold pain threshold & .10 & -.22 & .18 & .14 & .27 & -.11 & .08 & -.24 & .04 & -.13 \\
\hline Cold pain tolerance & .20 & .05 & .14 & $.29^{*}$ & $.35^{*}$ & -.07 & .11 & $-.34^{*}$ & .28 & .11 \\
\hline $40^{\circ} \mathrm{C}$ intensity & -.10 & $\ldots$ & $.35^{*}$ & $\ldots$ & $.34^{*}$ & $\ldots$ & .07 & $\ldots$ & -.14 & $\ldots$ \\
\hline $42^{\circ} \mathrm{C}$ intensity & .00 & .01 & $.39^{*}$ & .18 & $.37^{*}$ & -.09 & .28 & .01 & -.09 & .01 \\
\hline $44^{\circ} \mathrm{C}$ intensity & .20 & .14 & $.41^{* *}$ & .23 & $.38^{*}$ & -.14 & $.50^{* *}$ & -.10 & .16 & .08 \\
\hline $46^{\circ} \mathrm{C}$ intensity & .16 & .00 & .27 & .10 & .24 & .12 & $.47^{* *}$ & -.14 & .20 & .02 \\
\hline $48^{\circ} \mathrm{C}$ intensity & .08 & .02 & .09 & .16 & .08 & .27 & $.34^{*}$ & -.01 & .20 & .16 \\
\hline $50^{\circ} \mathrm{C}$ intensity & .03 & .17 & .02 & $.29^{*}$ & .21 & .22 & .14 & .02 & .06 & .19 \\
\hline $10^{\circ} \mathrm{C}$ intensity & .23 & .12 & $.39^{* *}$ & -.17 & .03 & .12 & .29 & -.04 & .19 & .06 \\
\hline $8^{\circ} \mathrm{C}$ intensity & $.39^{* *}$ & .04 & $.42^{* *}$ & -.08 & .23 & .10 & $.37^{*}$ & -.08 & $.37^{*}$ & .04 \\
\hline $6^{\circ} \mathrm{C}$ intensity & $.31^{*}$ & -.01 & $.43^{* *}$ & -.09 & $.31^{*}$ & .14 & $.41^{* *}$ & -.09 & .20 & .01 \\
\hline $4^{\circ} \mathrm{C}$ intensity & .24 & .03 & $.44^{* *}$ & -.02 & $.40^{* *}$ & .17 & $.39^{* *}$ & -.08 & .12 & .04 \\
\hline $2^{\circ} \mathrm{C}$ intensity & $.35^{*}$ & -.02 & $.41^{* *}$ & -.05 & $.50^{* * *}$ & .20 & $.39^{* *}$ & -.06 & .28 & .06 \\
\hline $0^{\circ} \mathrm{C}$ intensity & .30 & -.09 & $.41^{* *}$ & -.06 & $.60^{* *}$ & .16 & $.35^{*}$ & -.10 & .20 & -.02 \\
\hline
\end{tabular}

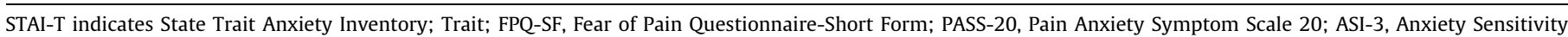
Index 3; and BDI-II, Beck Depression Inventory II.

a Scores did not vary.

${ }^{*} P<.05$

*** $P<.01$.

Table 4

Regressing pain variables in men with STAI-T, FPQ-SF, PASS-20, ASI-3, and BDI-II scores.

\begin{tabular}{|c|c|c|c|}
\hline $\begin{array}{l}\text { Dependent } \\
\text { variable }\end{array}$ & $R^{2}$ & $F$ & $\begin{array}{l}\text { Variables accounting for unique } \\
\text { variance }\end{array}$ \\
\hline Heat pain threshold & 0.11 & 0.93 & PASS-20 $(\beta=-.34)$ \\
\hline Heat pain tolerance & 0.18 & 1.66 & PASS-20 $(\beta=-.37) ;$ ASI-3 $(\beta=.43)$ \\
\hline Cold pain threshold & 0.09 & 0.69 & \\
\hline Cold pain tolerance & 0.22 & 2.11 & PASS-20 $(\beta=.42)$ \\
\hline $40^{\circ} \mathrm{C}$ intensity & 0.21 & 2.03 & \\
\hline $42^{\circ} \mathrm{C}$ intensity & 0.29 & $3.06^{*}$ & $\operatorname{ASI}-3(\beta=.35)$ \\
\hline $44^{\circ} \mathrm{C}$ intensity & 0.27 & $4.08^{* *}$ & ASI-3 $(\beta=.50)$ \\
\hline $46^{\circ} \mathrm{C}$ intensity & 0.25 & $2.51^{*}$ & ASI- $3(\beta=.52)$ \\
\hline $48^{\circ} \mathrm{C}$ intensity & 0.16 & 1.41 & ASI-3 $(\beta=.43)$ \\
\hline $50^{\circ} \mathrm{C}$ intensity & 0.07 & 0.53 & \\
\hline $10^{\circ} \mathrm{C}$ intensity & 0.25 & $2.42^{*}$ & FPQ-SF $(\beta=.43)$ \\
\hline $8^{\circ} \mathrm{C}$ intensity & 0.19 & $2.90^{*}$ & FPQ-SF $(\beta=.34)$ \\
\hline $6^{\circ} \mathrm{C}$ intensity & 0.29 & $3.06^{*}$ & FPQ-SF $(\beta=.31)$ \\
\hline $4^{\circ} \mathrm{C}$ intensity & 0.31 & $3.37^{*}$ & FPQ-SF $(\beta=.29)$ \\
\hline $2^{\circ} \mathrm{C}$ intensity & 0.35 & $3.95^{* *}$ & PASS-20 $(\beta=.34)$ \\
\hline $0^{\circ} \mathrm{C}$ intensity & 0.41 & $5.10^{* *}$ & PASS-20 $(\beta=.48)$ \\
\hline
\end{tabular}

STAI-T indicates State Trait Anxiety Inventory; Trait; FPQ-SF, Fear of Pain Questionnaire-Short Form; PASS-20, Pain Anxiety Symptom Scale 20; ASI-3, Anxiety Sensitivity Index 3; and BDI-II, Beck Depression Inventory II.

${ }^{*} P<.05$

${ }^{*} P<.05$.

significantly predicted variance in all cold pain intensity ratings in men (ie, $10^{\circ} \mathrm{C}, 8^{\circ} \mathrm{C}, 6^{\circ} \mathrm{C}, 4^{\circ} \mathrm{C}, 2^{\circ} \mathrm{C}, 0^{\circ} \mathrm{C}$ ), with variance accounted for increasing steadily as temperatures became more extreme (ie, colder), finally accounting for a substantive minority (41\%) of variance in pain intensity ratings for $0^{\circ} \mathrm{C}$. The ASI-3 score was the only variable to predict unique variance in the heat pain intensity ratings and was associated with higher intensity ratings. FPQ-SF scores predicted unique variance in milder cold pain intensity ratings (ie, $10^{\circ} \mathrm{C}, 8^{\circ} \mathrm{C}, 6^{\circ} \mathrm{C}, 4^{\circ} \mathrm{C}$ ) while PASS-20 scores predicted unique variance in more extreme cold pain intensity scores $\left(2^{\circ} \mathrm{C}\right.$ and $\left.0^{\circ} \mathrm{C}\right)$.

\section{Discussion}

The current investigation explored the associations among trait anxiety, pain-related anxiety constructs, depression symptoms, and experimental pain perception between sexes. The findings suggest that pain-related anxiety constructs, but not trait anxiety,
Table 5

Regressing pain variables in women with STAI-T, FPQ-SF, PASS-20, ASI-3, and BDI-II scores.

\begin{tabular}{llll}
\hline Dependent variable & $R^{2}$ & $F$ & $\begin{array}{l}\text { Variables accounting for unique } \\
\text { variance }\end{array}$ \\
\hline Heat pain threshold & 0.17 & 1.84 & FPQ-SF $(\beta=-.39)$ \\
Heat pain tolerance & 0.28 & $3.58^{* *}$ & FPQ-SF $(\beta=-.38)$; ASI-3 $(\beta=.39)$ \\
Cold pain threshold & 0.13 & 1.38 & \\
Cold pain tolerance & 0.33 & $4.46^{* *}$ & FPQ-SF $(\beta=.36) ;$ ASI-3 $(\beta=-.58)$ \\
$40^{\circ} \mathrm{C}$ intensity & $\ldots{ }^{a}$ & $\ldots{ }^{a}$ & $\ldots$ \\
$42^{\circ} \mathrm{C}$ intensity & 0.06 & 0.62 & \\
$44^{\circ} \mathrm{C}$ intensity & 0.14 & 1.49 & FPQ-SF $(\beta=.31)$ \\
$46^{\circ} \mathrm{C}$ intensity & 0.08 & 0.85 & ASI-3 $(\beta=-.33)$ \\
$48^{\circ} \mathrm{C}$ intensity & 0.14 & 1.52 & PASS-20 $(\beta=.35)$ \\
$50^{\circ} \mathrm{C}$ intensity & 0.15 & 1.62 & \\
$10^{\circ} \mathrm{C}$ intensity & 0.10 & 1.09 & \\
$8^{\circ} \mathrm{C}$ intensity & 0.06 & 0.58 & \\
$6^{\circ} \mathrm{C}$ intensity & 0.08 & 0.78 & PASS-20 $(\beta=.32)$ \\
$4^{\circ} \mathrm{C}$ intensity & 0.09 & 0.89 & PASS-20 $(\beta=.34)$ \\
$2^{\circ} \mathrm{C}$ intensity & 0.10 & 1.05 & PASS-20 $(\beta=.36)$ \\
$0^{\circ} \mathrm{C}$ intensity & 0.10 & 0.98 & PASS-20 $(\beta=.35)$ \\
\hline
\end{tabular}

STAI-T indicates State Trait Anxiety Inventory; Trait; FPQ-SF, Fear of Pain Questionnaire-Short Form; PASS-20, Pain Anxiety Symptom Scale 20; ASI-3, Anxiety Sensitivity Index 3; and BDI-II, Beck Depression Inventory II.

a Scores did not vary.

*** $P<.05$.

are most associated with pain perception in men and women. Trait anxiety was associated with pain perception for only 3 indices of pain perception, and only for cold pain intensity ratings for men. Moreover, trait anxiety did not predict unique variance in pain perception within any regression. This result contrasts with previous findings $[30,44]$ and may be a function of how variance in other pain-related anxiety constructs was controlled for.

Women exhibited lower pain threshold and tolerance levels relative to men, but not greater ratings of pain intensity to stimuli of fixed intensity, which is consistent with previous studies $[26,29,40,55]$. The relationships between the psychological constructs and pain perception differed markedly between men and women. Indeed, in every instance in which a psychological and pain variable were correlated within one sex, the relationship was not present in the other sex. Similarly, the regression analyses predicted significant variance in pain intensity ratings in men but not women, and predicted pain tolerance levels in women but not 


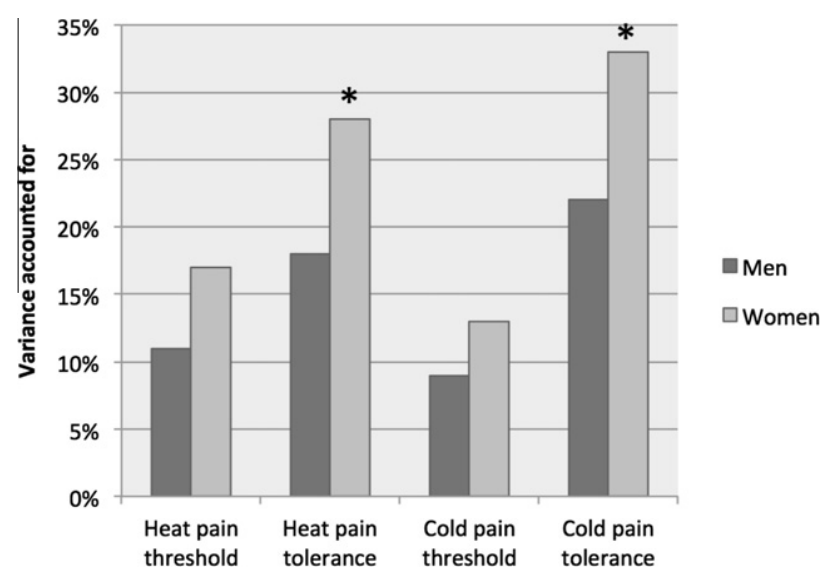

Fig. 1. Variance accounted for by psychological variables (State Trait Anxiety Inventory-Trait, Fear of Pain Questionnaire-Short Form, Pain Anxiety Symptom Scale-20, Anxiety Sensitivity Index-3, Beck Depression Inventory-II) in heat and cold pain threshold and tolerance levels for men and women. Asterisks indicate overall regression equations that predict statistically significant variance.

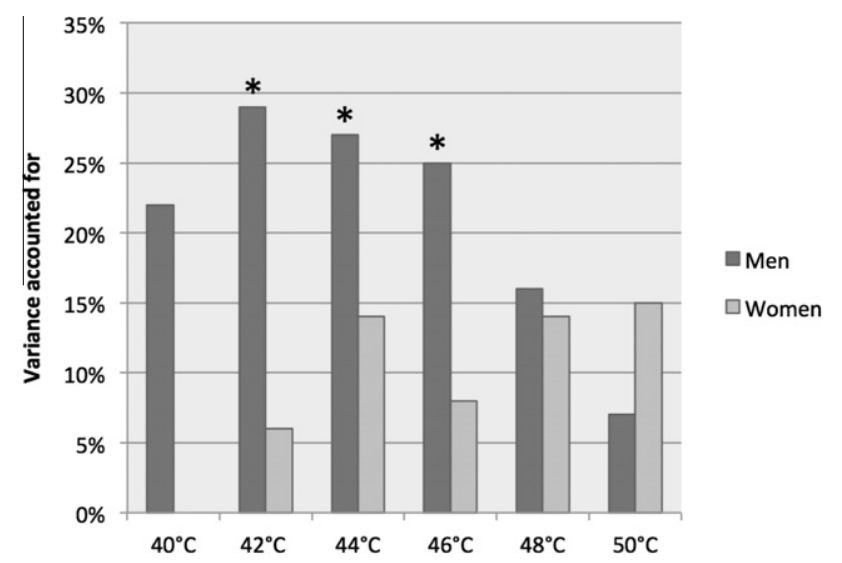

Fig. 2. Variance accounted for by psychological variables (State Trait Anxiety Inventory-Trait, Fear of Pain Questionnaire-Short Form, Pain Anxiety Symptom Scale-20, Anxiety Sensitivity Index-3, Beck Depression Inventory-II) in heat pain intensity ratings for men and women. Asterisks indicate overall regression equations that predict statistically significant variance.

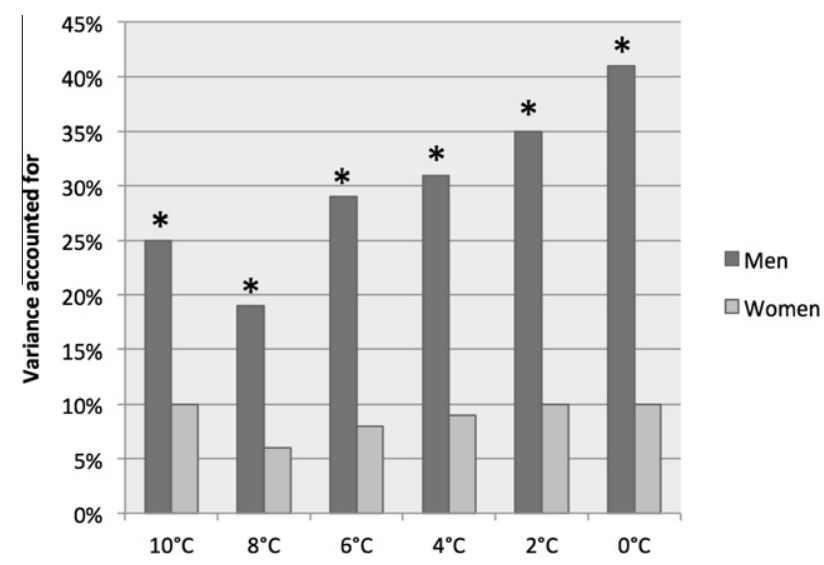

Fig. 3. Variance accounted for by psychological variables (State Trait Anxiety Inventory-Trait, Fear of Pain Questionnaire-Short Form, Pain Anxiety Symptom Scale-20, Anxiety Sensitivity Index-3, Beck Depression Inventory-II) in cold pain intensity ratings for men and women. Asterisks indicate overall regression equations that predict statistically significant variance. men. These findings strongly suggest that pain-related anxiety constructs contribute to experimental pain perception differentially between sexes; however, these relationships are not necessarily stronger in men, as concluded in previous studies [20,21,28].

The mechanism behind this novel sex difference is unknown, but might be explained by 2 different phenomena. Pain-related anxiety constructs could impact the perception of mild to moderate pain most in men, while contributing to perception of extreme pain in women (ie, nearly intolerable pain). Alternatively, pain-related anxiety constructs could influence verbal pain responses most in men (eg, while using a NRS), and influence behavioral pain responses most in women (eg, pressing a button to stop stimulus). More research is needed to explore these possibilities.

Depression symptoms were only associated with pain intensity ratings for one temperature $\left(8^{\circ} \mathrm{C}\right)$, only in men, and did not predict unique variance beyond other variables in any of the regression analyses. These findings suggest that self-reported depression symptoms, at least in nonclinical populations, may not be associated with experimental pain perception to any practical extent. These findings diverge from previous studies demonstrating that individuals with clinical depression differ from healthy controls in terms of pain perception [15]. This divergence may be because pain perception is only associated with depression symptoms in relatively extreme and clinical presentations, or because the current investigation also controlled for variance in other salient constructs.

The current findings suggest that trait anxiety and depression symptoms, at least in nonclinical populations, are not of primary influence on pain perception in either sex; however, no such relationship between fear of pain, pain-related anxiety, and anxiety sensitivity and pain perception can be summarized. The results suggest that none of these constructs is primarily associated with pain perception, calling for research examining the interrelationships between fear of pain, pain-related anxiety, and anxiety sensitivity. The constructs are believed to be factorially and theoretically distinct $[4,5,9]$, which is supported by the small to moderate correlations between these variables presented in the current data; however, more research is needed to determine if these represent independent or overlapping constructs in the context of pain perception. Perhaps a higher-order factor, such as fear of physical discomfort or negative attitudes toward pain, explains why these 3 variables are associated with hyperalgesia. Nevertheless, results from the regression analyses suggest that these constructs are not redundant. Indeed, anxiety sensitivity predicted unique variance in increased heat and cold pain tolerance in women and heat pain in men (ie, hypoalgesia), a relationship that was not present with fear of pain and pain-related anxiety. This novel finding contradicts previous reports that anxiety sensitivity is associated with decreased pain tolerance [39]. Methodological differences, such as the method of pain induction (ie, digitally controlled thermode vs cold pressor) or the variables controlled for may have allowed the identification of this unexpected finding, which leaves room for interpretation. One possibility is that anxiety sensitivity facilitates a form of stress-induced analgesia, a pain suppression response occurring when facing anxiety-provoking stimuli [2]; however, why this would be unique to anxiety sensitivity is unknown. Alternatively, this finding could represent a statistical artifact; but, given the effect was identified in both sexes and in different pain trials and modalities, this seems relatively unlikely. More research is needed to explore this phenomenon.

The current findings provide several directions for future research. Sex-specific effects in pain perception suggest that researchers should attempt to examine relationships independently in each sex, rather than removing variance by means of including sex as a variable in a linear model (eg, regression, analysis of covariance $[27,28,33])$. Similarly, the different pain modalities 
(ie, heat and cold) and measures of pain perception (eg, intensity, tolerance) exhibited different findings and future research may benefit from utilizing numerous pain induction techniques and measures. The relationship between the psychological variables and pain perception modality (eg, verbal rating, pressing button) also warrants further research. If psychological variables influence behavioral (eg, avoidance) and verbal responses to pain (eg, complaints about pain) differently between sexes, this caveat may bare relevance in clinical endeavors. Fear of pain, pain-related anxiety, and anxiety sensitivity were the variables most associated with pain perception, and these could conceivably exacerbate perceptions that pain is threatening and to be avoided. The nature of these relationships may inform mechanisms by which altered pain perception influences the transition of acute pain to chronic pain by fostering avoidance of activities that would promote healing (eg, exercise) [4,5,35,57]. Lastly, researchers in this area may benefit most from focusing on anxiety variables related to pain rather than general anxiety.

Several limitations in the present investigation suggest future research directions. The investigation expanded beyond the almost exclusive use of the cold-pressor task in this area [23,24,28,39,49] and allows for generalization to both heat and cold thermal pain; however, future research may benefit from exploring the currently presented associations using other pain induction techniques (eg, chemical, electric). Several participants were able to withstand the highest or lowest temperatures without reporting that the pain had become intolerable, precluding an accurate estimation of their cold and heat pain tolerance levels and reducing the amount of variance in pain tolerance data. Future studies would benefit from pain stimuli that reach levels of intolerance in all participants. The current investigation, along with others in this area [20,31], included the State-Trait Anxiety Inventory, State [48]. The measure was completed before quantitative sensory testing, which does not provide a valid index of state anxiety during the experimental procedure; consequently, it was excluded from the current report and the analyses. Future research may benefit from measuring state anxiety throughout testing, perhaps by visual analogue scale [12], and examining which traits are associated with state anxiety during testing and how these are associated with pain perception. Similarly, researchers could extend the current study by exploring sex-specific relationships between pain perception and other painrelated anxiety constructs (eg, pain catastrophizing). Pain intensity and pain unpleasantness were both assessed, as recommended in previous literature $[11,47]$; but, these measures were largely redundant in the current investigation. This redundancy may be due to temporal proximity in measuring both of these variables, which may have been avoided by conducting separate trials to assess pain intensity and unpleasantness for each temperature. Moreover, only a male experimenter was present during quantitative sensory testing, which may have influenced the reactions of participants. The current investigation included nonclinical participants who did not self-report any of several conditions (eg, chronic pain, medical conditions, mental disorders), which controlled for confounds but may preclude the generalizability of the findings, most notably to clinical populations (eg, to clinical levels of depression, to anxiety disorders) due to limited variance on the measures of interest (eg, the BDI-II). The size of the sample was comparable to other studies, but may not have allowed relatively small effects to reach statistical significance. A final and important limitation of the present investigation, and of other studies in this area, is the inability to infer causal relationships (eg, if psychological variables cause changes in pain perception, or vice versa). Longitudinal and experimental studies are necessary to answer these questions of causation.

To summarize, the current investigation expanded on previous literature by demonstrating the following findings. First, pain-related anxiety constructs, more than general trait anxiety, are associated with pain perception. Second, these constructs seem to demonstrate sex-specific effects, being most associated with self-reported pain intensity in men and pain tolerance levels in women. Third, depression symptoms in nonclinical populations do not seem to be systematically associated with altered pain perception in either sex. Fourth, no systematic relationships were identified that allow conclusions regarding how fear of pain, pain-related anxiety, and anxiety sensitivity may be differentially associated with pain perception. The findings provide several directions for future research and support that fear and anxiety are important features that contribute to hyperalgesia in both men and women; however, research is needed to explore these effects in clinical samples and to explore the similarities and differences between fear of pain, pain-related anxiety, and anxiety sensitivity in the context of pain perception.

\section{Conflict of interest statement}

The authors report no conflict of interest.

\section{Acknowledgments}

MAT was supported by a Canadian Institutes of Health research doctoral award (FRN 113434). The current research was also made possible by a Canadian Institutes of Health Research master's award granted to PGW (FRN 89120) and by a Canadian Institutes of Health Research operating grant held by GJGA (FRN 86658).

\section{References}

[1] Abrams MP, Carleton RN, Asmundson GJG. An exploration of the psychometric properties of the PASS-20 with a nonclinical sample. J Pain 2007;8:879-86.

[2] Amit Z, Galina ZH. Stress-induced analgesia-adaptive pain suppression. Physiol Rev 1986;66:1091-120.

[3] Asmundson GJG, Bovell CV, Carleton RN, McWilliams LA. The Fear of Pain Questionnaire-Short Form (FPQ-SF): factorial validity and psychometric properties. PAIN ${ }^{\circledR} 2008 ; 134: 51-8$.

[4] Asmundson GJG, Norton PJ, Norton GR. Beyond pain: the role of fear and avoidance in chronicity. Clin Psychol Rev 1999;19:97-119.

[5] Asmundson GJG, Katz J. Understanding the co-occurrence of anxiety disorders and chronic pain: state-of-the-art. Depress Anxiety 2009;26:888-901.

[6] Bar KJ, Brehm S, Boettger MK, Boettger S, Wagner G, Sauer H. Pain perception in major depression depends on pain modality. PAIN ${ }^{\circledR} 2005 ; 117: 97-103$.

[7] Beck AT, Steer RA, Ball R, Ranieri W. Comparison of Beck Depression Inventories IA and II in psychiatric outpatients. J Pers Assess 1996;67:588-97.

[8] Beck AT, Steer RA, Brown GK. BDI-II: Beck Depression Inventory manual. San Antonio, TX: Psychological Corp, Harcourt Brace; 1996.

[9] Carleton RN, Asmundson GJG. The multidimensionality of fear of pain: construct independence for the Fear of Pain Questionnaire-Short Form and the Pain Anxiety Symptoms Scale-20. J Pain 2009;10:29-37.

[10] Coons MJ, Hadjistavropoulos HD, Asmundson GJG. Factor structure and psychometric properties of the Pain Anxiety Symptoms Scale-20 in a community physiotherapy clinic sample. Eur J Pain 2004;8:511-6.

[11] Cruccu G, Sommer C, Anand P, Attal N, Baron R, Garcia-Larrea L, Haanpaa M, Jensen TS, Serra J, Treede RD. EFNS guidelines on neuropathic pain assessment: revised 2009. Eur J Neurol 2010;17:1010-8.

[12] Davey HM, Barratt AL, Butow PN, Deeks JJ. A one-item question with a Likert or visual analog scale adequately measured current anxiety. J Clin Epidemiol 2007:60:356-60.

[13] Defrin R, Ginzburg K, Solomon Z, Polad E, Bloch M, Govezensky M, Schreiber S. Quantitative testing of pain perception in subjects with PTSD-implications for the mechanism of the coexistence between PTSD and chronic pain. PAIN ${ }^{\circledR}$ 2008;138:450-9.

[14] De Peuter S, Van Diest I, Vansteenwegen D, Van den Bergh O, Vlaeyen JW. Understanding fear of pain in chronic pain: interoceptive fear conditioning as a novel approach. Eur J Pain 2011;15:889-94

[15] Dickens C, McGowan L, Dale S. Impact of depression on experimental pain perception: a systematic review of the literature with meta-analysis. Psychosom Med 2003:65:369-75.

[16] Edwards R, Augustson EM, Fillingim R. Sex-specific effects of pain-related anxiety on adjustment to chronic pain. Clin J Pain 2000;16:46-53.

[17] Egloff B, Schmukle SC. Gender differences in implicit and explicit anxiety measures. Pers Indiv Differ 2004;36:1807-15.

[18] Fillingim RB. Sex, gender, and pain: women and men really are different. Curr Rev Pain 2000;4:24-30. 
[19] Fillingim RB, Edwards RR. Is self-reported childhood abuse history associated with pain perception among healthy young women and men? Clin J Pain 2005;21:387-97.

[20] Fillingim RB, Keefe FJ, Light KC, Booker DK, Maixner W. The influence of gender and psychological factors on pain perception. J Gend Cult Health 1996;1:21-36.

[21] Fillingim RB, King CD, Ribeiro-Dasilva MC, Rahim-Williams B, Riley III JL. Sex, gender, and pain: a review of recent clinical and experimental findings. J Pain 2009;10:447-85.

[22] Fillingim RB, Maixner W, Sigurdsson A, Kincaid S. Sexual and physical abuse history in subjects with temporomandibular disorders: relationship to clinical variables, pain sensitivity, and psychologic factors. J Orofacial Pain 1997; 11:48-57.

[23] George SZ, Dannecker EA, Robinson ME. Fear of pain, not pain catastrophizing, predicts acute pain intensity, but neither factor predicts tolerance or blood pressure reactivity: an experimental investigation in pain-free individuals. Eur J Pain 2006; 10:457-65.

[24] George SZ, Hirsh AT. Psychologic influence on experimental pain sensitivity and clinical pain intensity for patients with shoulder pain. J Pain 2009;10:293-9.

[25] Geuze E, Westenberg HGM, Jochims A, de Kloet CS, Bohus M, Vermetten E, Schmahl C. Altered pain processing in veterans with posttraumatic stress disorder. Arch Gen Psychiatry 2007;64:76-85.

[26] Gibson SJ, Helme RD. Age-related differences in pain perception and report. Clin Geriatr Med 2001;17:433-56.

[27] Gonzalez A, Zvolensky MJ, Hogan J, McLeish AC, Weibust KS. Anxiety sensitivity and pain-related anxiety in the prediction of fear responding to bodily sensations: a laboratory test. J Psychosom Res 2011;70:258-66.

[28] Hirsh AT, George SZ, Bialosky JE, Robinson ME. Fear of pain, pain catastrophizing, and acute pain perception: relative prediction and timing of assessment. J Pain 2008;9:806-12.

[29] Jackson T, Iezzi T, Chen H, Ebnet S, Eglitis K. Gender, interpersonal transactions, and the perception of pain: an experimental analysis. J Pain 2005;6:228-36.

[30] James JE, Hardardottir D. Influence of attention focus and trait anxiety on tolerance of acute pain. Br J Health Psychol 2002;7:149-62.

[31] Jones A, Zachariae R. Investigation of the interactive effects of gender and psychological factors on pain response. Br J Health Psychol 2004;9:405-18.

[32] Jones A, Zachariae R, Arendt-Nielsen L. Dispositional anxiety and the experience of pain: gender-specific effects. Eur J Pain 2003;7:387-95.

[33] Katz J, Martin AL, Page MG, Calleri V. Alexithymia and fear of pain independently predict heat pain intensity ratings among undergraduate university students. Pain Res Manage 2009;14:299-305.

[34] Lautenbacher S, Fillingim RB, editors. Pathophysiology of pain perception. New York: Kluwer Academic; 2004.

[35] Lethem J, Slade PD, Troup JD, Bentley G. Outline of a fear-avoidance model of exaggerated pain perception-I. Behav Res Ther 1983;21:401-8.

[36] McCracken LM, Dhingra L. A short version of the Pain Anxiety Symptoms Scale (PASS-20): preliminary development and validity. Pain Res Manage 2002;7:45-50.

[37] Nielsen J, Arendt-Nielsen L. The influence of rate of temperature change and peak stimulus duration on pain intensity and quality. Somatosens Mot Res 1998;15:220-9.

[38] Nolen-Hoeksema S. Sex differences in unipolar depression: evidence and theory. Psychol Bull 1987;101:259-82.

[39] Ocanez KL, McHugh RK, Otto MW. A meta-analytic review of the association between anxiety sensitivity and pain. Depress Anxiety 2010;27:760-7.
[40] Paller CJ, Campbell CM, Edwards RR, Dobs AS. Sex-based differences in pain perception and treatment. Pain Med 2009;10:289-99.

[41] Pitman RK, van der Kolk BA, Orr SP, Greenberg MS. Naloxone-reversible analgesic response to combat-related stimuli in posttraumatic stress disorder. A pilot study. Arch Gen Psychiatry 1990;47:541-4.

[42] Price DD, Patel R, Robinson ME, Staud R. Characteristics of electronic visual analogue and numerical scales for ratings of experimental pain in healthy subjects and fibromyalgia patients. PAIN ${ }^{\circledR} 2008 ; 140: 158-66$.

[43] Riley III JL, Robinson ME, Wise EA, Myers CD, Fillingim RB. Sex differences in the perception of noxious experimental stimuli: a meta-analysis. PAIN ${ }^{\circledR}$ 1998; 74:181-7.

[44] Robinson ME, Dannecker EA, George SZ, Otis J, Atchison JW, Fillingim RB. Sex differences in the associations among psychological factors and pain report: a novel psychophysical study of patients with chronic low back pain. J Pain 2005;6:463-70.

[45] Robinson ME, Riley JI, Myers CD. Psychosocial contributions to sex-related differences in pain responses. In: Fillingim RB, editor. Sex, gender, and pain. Seattle: IASP Press; 2000. p. 41-68.

[46] Rolke R, Baron R, Maier C, Tolle TR, Treede RD, Beyer A, Binder A, Birbaumer N, Birklein F, Botefur IC, Braune S, Flor H, Huge V, Klug R, Landwehrmeyer GB, Magerl W, Maihofner C, Rolko C, Schaub C, Scherens A, Sprenger T, Valet M, Wasserka B. Quantitative sensory testing in the German Research Network on Neuropathic Pain (DFNS): standardized protocol and reference values. PAIN ${ }^{\circledR}$ 2006;123:231-43.

[47] Smith WB, Gracely RH, Safer MA. The meaning of pain: cancer patients' rating and recall of pain intensity and affect. PAIN ${ }^{\circledR} 1998 ; 78: 123-9$.

[48] Spielberger CD, Gorsuch RL, Lushene R, Vagg P, Jacobs GA. Manual for the State-Trait Anxiety Inventory STAI (form Y): self-evaluation questionnaire. Palo Alto, CA: Consulting Psychologists Press; 1983.

[49] Staats PS, Staats A, Hekmat H. The additive impact of anxiety and a placebo on pain. Pain Med 2001;2:267-79.

[50] Stewart SH, Taylor S, Baker JM. Gender differences in dimensions of anxiety sensitivity. J Anxiety Disord 1997;11:179-200.

[51] Sullivan MJL, Tripp DA, Santor D. Gender differences in pain and pain behavior: the role of catastrophizing. Cogn Ther Res 2000;24:121-34.

[52] Tang J, Gibson SJ. A psychophysical evaluation of the relationship between trait anxiety, pain perception, and induced state anxiety. J Pain 2005;6:612-9.

[53] Tashani OA, Alabas OA, Johnson MI. Cold pressor pain responses in healthy Libyans: effect of sex/gender, anxiety, and body size. Gend Med 2010;7:309-19.

[54] Taylor S, Zvolensky MJ, Cox BJ, Deacon B, Heimberg RG, Ledley DR, Abramowitz JS, Holaway RM, Sandin B, Stewart SH, Coles M, Eng W, Daly ES, Arrindell WA, Bouvard M, Cardenas SJ. Robust dimensions of anxiety sensitivity: development and initial validation of the Anxiety Sensitivity Index-3. Psychol Assess 2007;19:176-88.

[55] Thompson T, Keogh E, French CC, Davis R. Anxiety sensitivity and pain generalisability across noxious stimuli. PAIN ${ }^{\circledR} 2008 ; 134: 187-96$.

[56] Vlaeyen JW, de Jong J, Geilen M, Heuts PH, van Breukelen G. Graded exposure in vivo in the treatment of pain-related fear: a replicated single-case experimental design in four patients with chronic low back pain. Behav Res Ther 2001;39:151-66.

[57] Vlaeyen JW, Linton SJ. Fear-avoidance and its consequences in chronic musculoskeletal pain: a state of the art. PAIN ${ }^{\circledR} 2000 ; 85: 317-32$.

[58] Wald J, Taylor S, Chiri LR, Sica C. Posttraumatic stress disorder and chronic pain arising from motor vehicle accidents: efficacy of interoceptive exposure plus trauma-related exposure therapy. Cogn Behav Ther 2010;39:104-13. 